\title{
DATA ACQUISITION THROUGH THE MODEL AIRCRAFT FOR MAPPING PURPOSES
}

\author{
S. Karakis*, U. G. Sefercik*, C. Bayik* \\ *Zonguldak Karaelmas University, Department of Geodesy and Photogrammetry Engineering, Zonguldak, Turkey, \\ jeodezi@hotmail.com
}

KEY WORDS: Model aircraft, Photogrammetry, Non-metric camera, Accuracy

\begin{abstract}
Photogrammetry and remote sensing have become indispensable in today's surveying with the emerging technologies. Some difficulties are being experienced in applications due to the incredible advances in imaging systems and increasing complexity of carrier platforms, used, in parallel with them. In this context, the most agreeable approach is the achievement of desired precision proportional with the requirements in shorter time span and the reduction of cost utilizing the most suitable mapping platform with basic systems. Towards these aims, a model aircraft, containing a non-metric camera, capturing images for mapping purposes, is considered to be employed in this study. Thus, this will lead to emerge a low cost imaging system. Within the study, besides using a high resolution digital non-metric camera and a carrier model aircraft, the previously produced maps of test field, derived from aerial photos, were used to conduct the analysis. The scope of this study is the integration of a model aircraft and a non-metric camera for mapping purposes to reduce very costly and time consuming photogrammetric map production for narrower areas. Also this will give rise to a method for the achievement of high cost aims with lower budgets. Using a model aircraft, instead of a real one, gives us an upper hand in repeating measurements anytime, desired, so that analyses can be made for the works that undergoes temporal changes. According to the aims of the study, a stereo model has been generated for the extraction of details from aerial photos, taken by the non-metric camera. Estimated results have been compared with 1/1000 scaled maps from photogrammetry and figured out their validity for using in narrower areas with high accuracy.
\end{abstract}

\section{INTRODUCTION}

In this study, advantages of the integration of a model aircraft and a non-metric camera are handled, for mapping purposes which provides low cost and time saving in comparison with today's photogrammetric map production period. It has been flown over a coastal area of Zonguldak city which placed at the west part of Black Sea region of Turkey. Suitable shot interval has been determined according to $60 \mathrm{~km}$ flying speed iteratively. In the same way, altitude is determined again according to frame size and Ground Sampling Distance (GSD). Taken images have been evaluated on Z/I Imagestation software and results have been compared with $1 / 1000$ scaled maps derived from large scale photogrammetry in 1997.

As parts of this study, test field, model aircraft, camera and platform are given sequentially and finally the application and conclusions are tried to be explained.

\section{TEST FIELD}

The test field is a small part of coastal strip in Zonguldak city, Turkey which lies through the west-Black Sea region and covers $2 \mathrm{~km} \times 0.5 \mathrm{~km}$ (lengthxwidth). The topography is nearly flat and suitable landing zones exist along the coastal strip. Test field is shown in Figure 1.

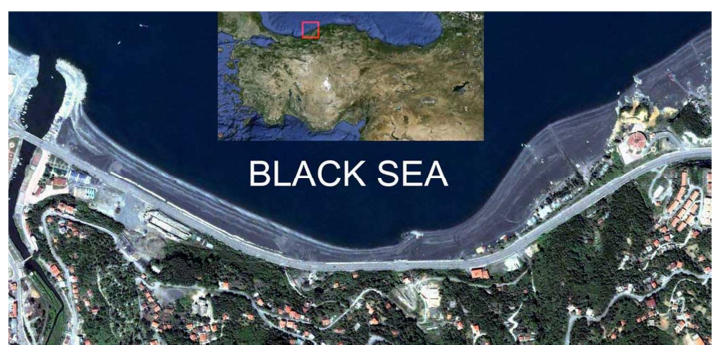

Figure 1 Zonguldak Coastal Test Field

\section{MODEL AIRCRAFT}

After the investigations considering the aims of the study, it has been decided to use a model aircraft which has low speed as stable. Thus a RTF (ready to fly) 60 size trainer model aircraft has been chosen. This model is both big enough for carrying camera system and slight that serves its transportation action. It has $0.60 \mathrm{in}^{3}$ gas powered engine which uses special model fuel formed with alcohol and oil contents. General view of aircraft has been shown in Figure 2.

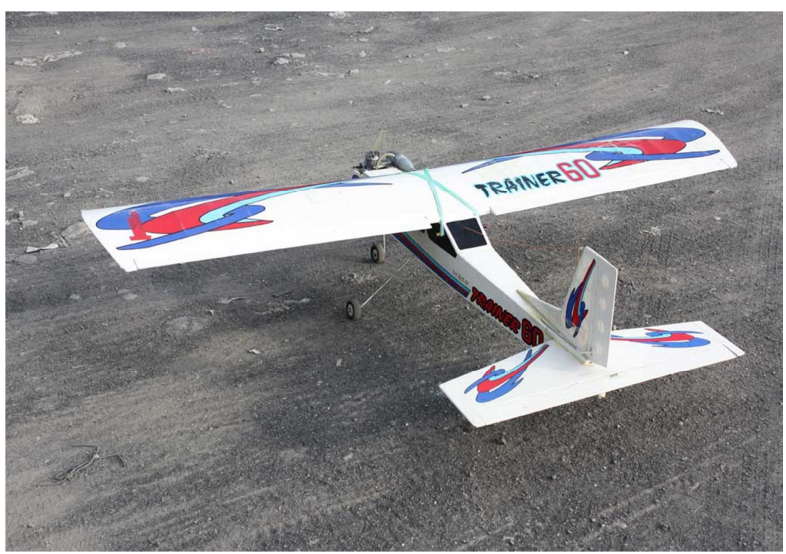

Figure 2 General View of Model Aircraft

Model aircraft has been controlled by a radio controlled $(\mathrm{R} / \mathrm{C})$ joy-stick and receiver. The R/C has 8 channels which serves both moving of aircraft and other processes. Four of them are used for general movements of aircraft and others for shutter or except processes etc. The model aircraft has $60 \mathrm{~km} / \mathrm{h}$ flying speed as stable. For this study it has been flown without camera for exercising on different weather conditions. Low altitude flying soon after taking off can be seen in Figure 3. 


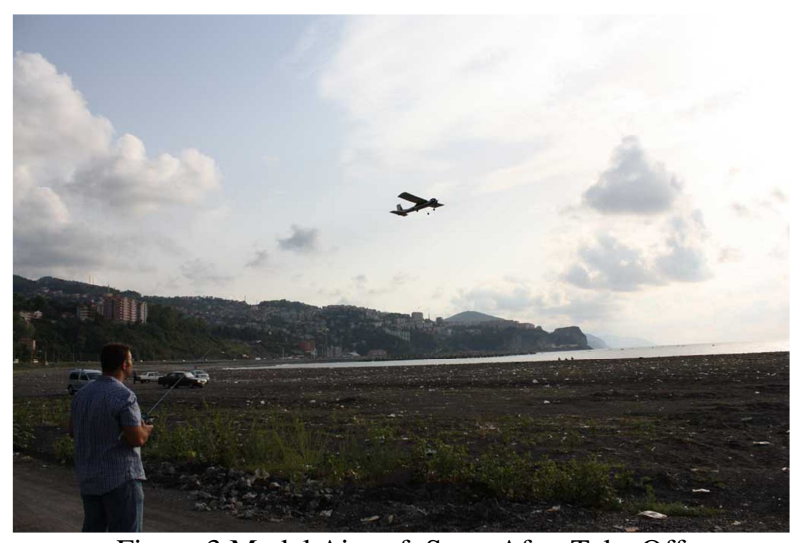

Figure 3 Model Aircraft Soon After Take Off

\section{CAMERA}

The Canon EOS450D has been used as a digital camera towards the aims of study. It has $12 \mathrm{MP}$ resolution and a lens which has sold basic kit with $18-55 \mathrm{~mm}$ adjustable focal length. Technical specifications of product which published by manufacturer are in Table 1 (URL 1).

Table 1 Canon EOS 450D Technical Specifications

\begin{tabular}{|l|c|}
\hline Resolution & 12.40 Mpixel \\
\hline Maximum resolution (frame) & $4272 \times 2848$ \\
\hline Sensor size (mm) & $22.2 \times 14.8$ \\
\hline Maximum shutter $(\mathrm{sec})$ & $1 / 4000$ \\
\hline Weight $(\mathrm{g})$ & 475 \\
\hline Sizes $(\mathrm{mm})$ & $129 \times 98 \times 62$ \\
\hline
\end{tabular}

\section{PLATFORM}

Even though it has been decided to use 8 channels R/C, for providing suitable andstable stereoscopic fields, hand controlled shots at $60 \mathrm{~km} / \mathrm{h}$ speed are not possible practically. Therefore it has been decided to use a control card which enables time control. For timing, a basic programmable chip has been selected with integrated crystal which enables easy circuit design. A timing program for chip has been written in $\mathrm{C}$ programming language and shot times have been checked iteratively.

The system has not an equipment which shows the speed of model aircraft, so a fixed position on throttle has been chosen for all practices.

For early exercises, chip has been programmed for $2 \mathrm{sec}$ shot interval but $\% 30$ overlapped images have been acquired as results in this manner. At the other exercises it has been programmed as $1 \mathrm{sec}$ and $\% 75$ overlapped images have been acquired. Hence, 1sec shot interval has been decided to use at the rest of application because of convenient overlapping area.

Even though it is called as $1 \mathrm{sec}$ or $2 \mathrm{sec}$, just quarter second time delay is existing between two shot times. Because the reaction time of camera shutter has been adjusted to $250 \mathrm{msec}$ in chip program. Therefore images have been taken with $1.25 \mathrm{sec}$ interval. The shutter circuit can be seen in Figure 4 .

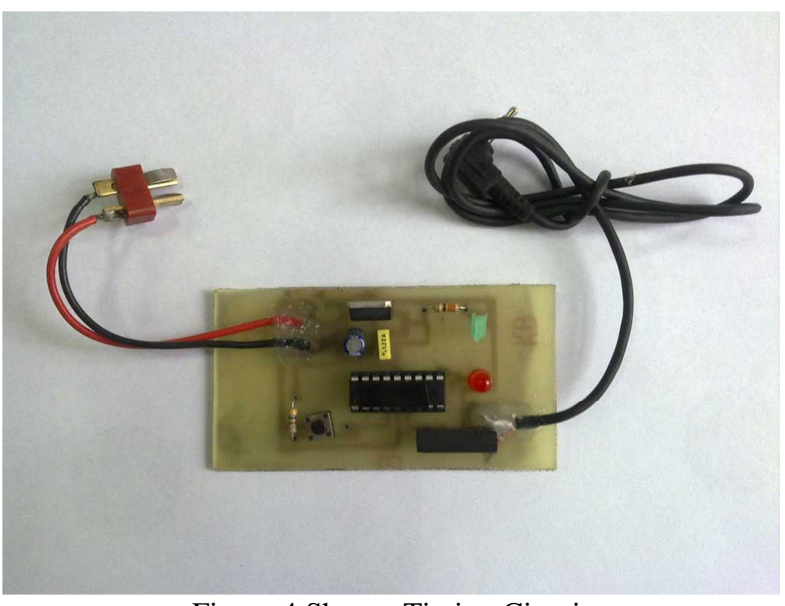

Figure 4 Shutter Timing Circuit

During shuttering time, another problem could be encountered by motion of aircraft which causes blur effect on images called motion blur. Conventional photogrammetric systems eliminate this problem using Forward Motion Compensation (FMC) or Time Delay Integration (TDI) technology. But similar technologies cannot be used in nonmetric cameras. That's why both a model aircraft which has low speed stability and a camera which has very fast shutter speed have been chosen. For motion blur a few base equations can be given. First is GSD which has been derived by approved flight altitude and sensor size shown below in equation 1 (Neumann, 2008).

$G S D=\frac{H}{c} \times C C D$ pixel size

$H \cong 250 m, \quad c=18 \mathrm{~mm}$

$\mathrm{CCD}$ pixel size $=5 \mu \mathrm{m}$

$G S D \cong 7 \mathrm{~cm}$

Second one is motion value during shutter time, along the flight way. For $60 \mathrm{~km} / \mathrm{h}$ speed motion $\mathrm{x}$ has been derived in equation 2 .

$x \cong$ Speed $\times$ shutter

Speed $\cong \frac{60 \mathrm{~km}}{\mathrm{~h}}$

shutter $=\frac{1}{4000} \mathrm{sec}$

$x \cong 4 m m$

No motion blur effect has been realized by motion which equals or smaller than quarter of GSD value iteratively. So it can be accepted that $4 \mathrm{~mm}$ motion value is not effective for $7 \mathrm{~cm}$ GSD value.

Camera has been placed in model aircraft between the landing gears as forwarded to down side. It has been adjusted as only the lens seen outside. Suchlike design makes possible both stability of aircraft and security of camera in case of unexpected crash period. Camera which placed on model aircraft can be shown in Figure 5. 


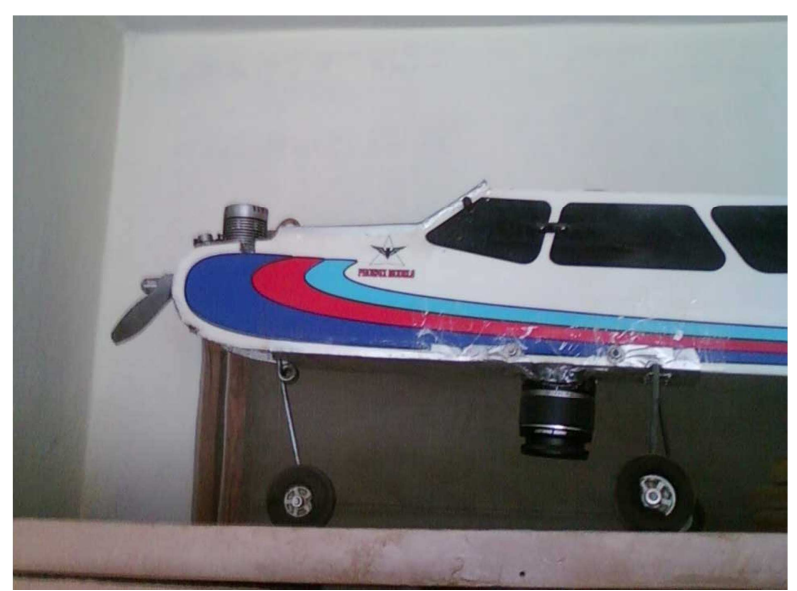

Figure 5 Camera on Model Aircraft

\section{APPLICATION}

In November 2010, flight has been carried out. Despite of low sun angle, suitable images were acquired. Along the coastal strip, different details have been imaged as roads, buildings, forest etc. Overlapping has been obtained $\% 75$ as expected. The biggest problem encountered was small frame size which caused more computation for whole model area, although good distributed ground control points (GCPs) have been chosen from the images and measured by GPS. A number of image samples are shown in Figure 6, 7 and 8 include different ground objects.

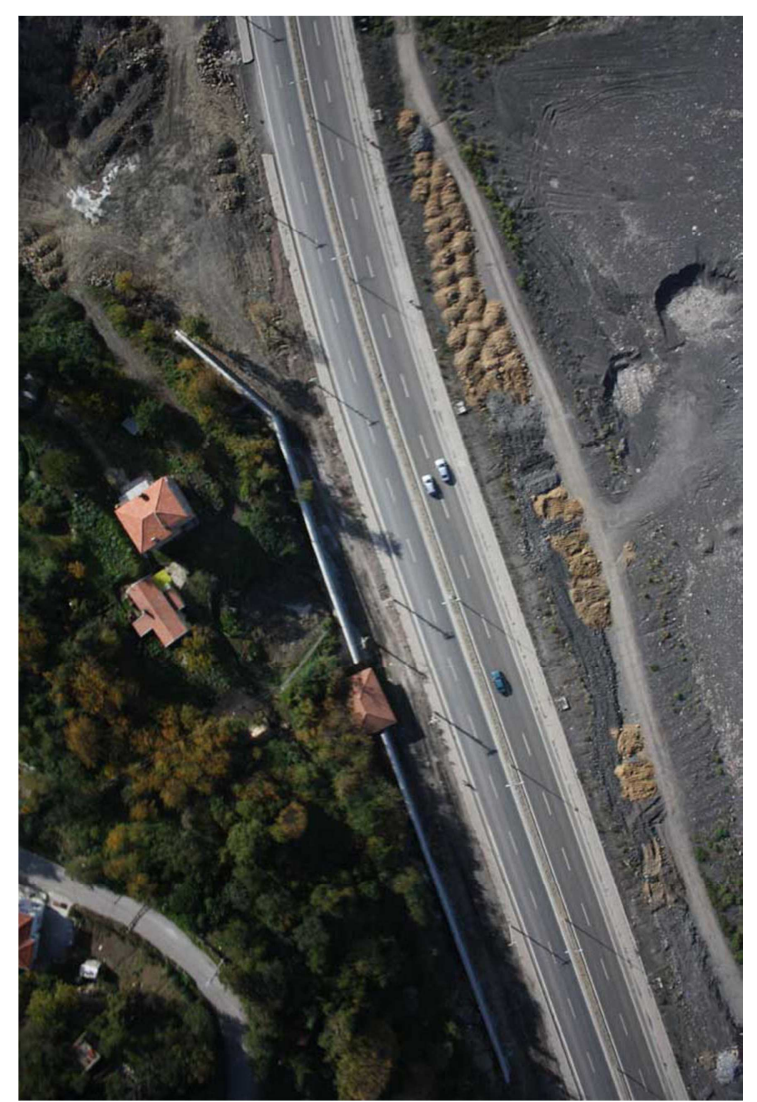

Figure 6 Sample for Road Details

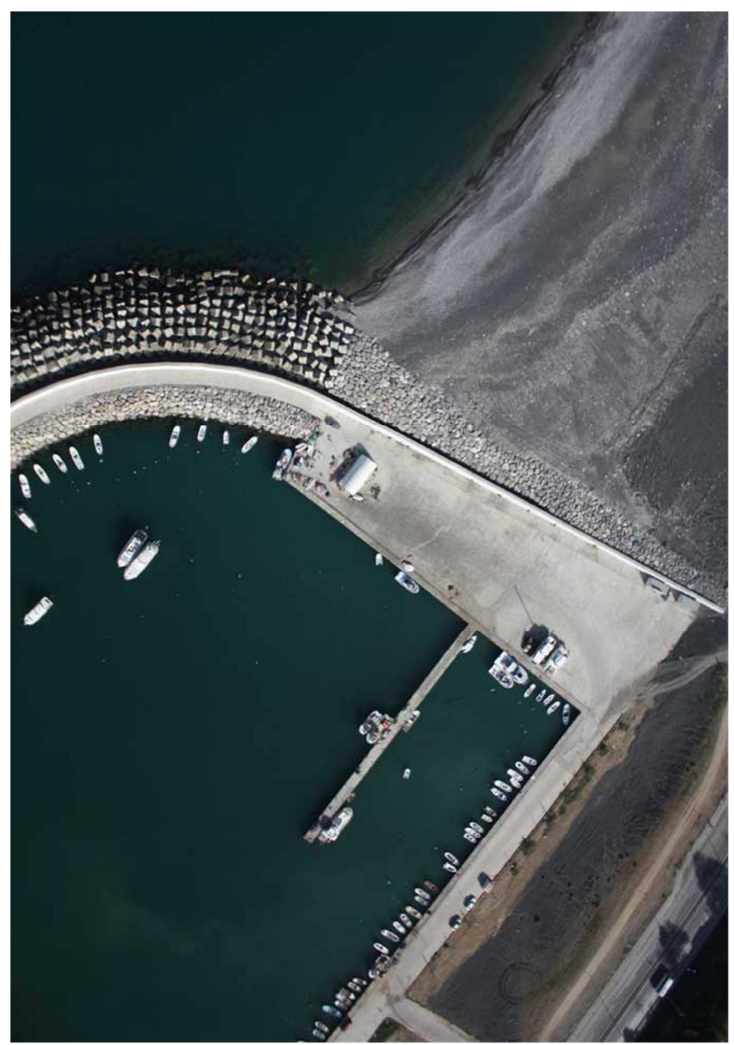

Figure 7 Sample for Hydrographic Details

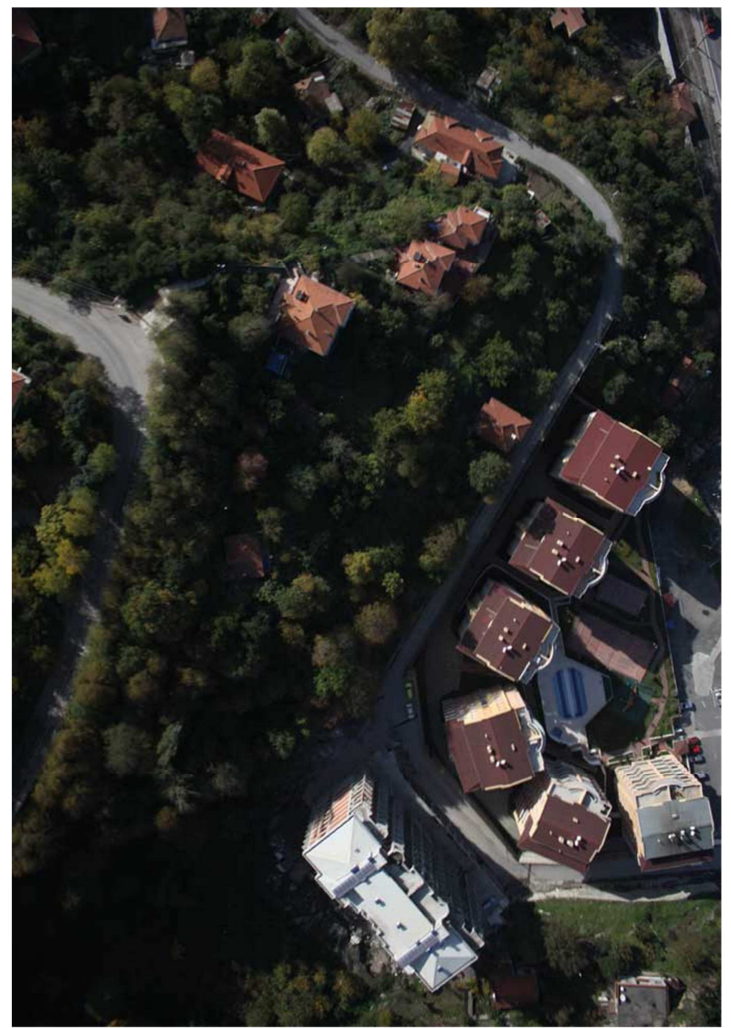

Figure 8 Sample for Urban and Urban Forest Areas

For the application, suitable stereo pair has been chosen which shows an area with different ground objects and elevations. Then model has been evaluated on $\mathrm{Z} / \mathrm{I}$ Imagestation software. Used stereo pair for the application can be seen in Figure 9 as a (left image of pair) and b (right image of pair). 


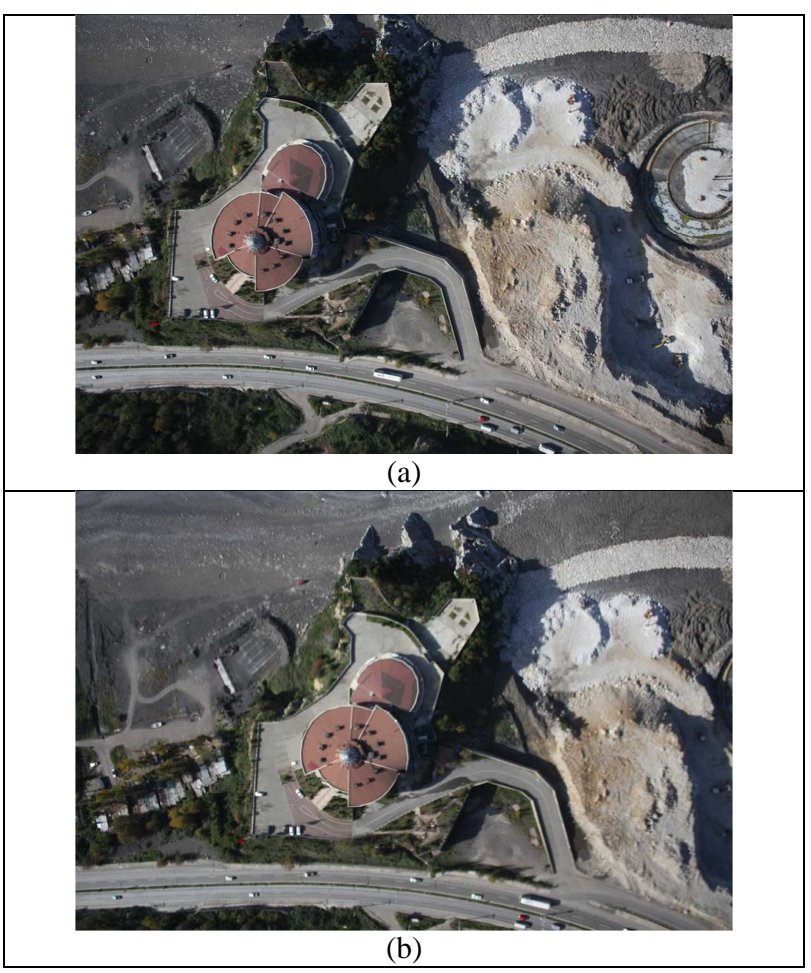

Figure 9 Stereo Pair Used for Application

Good distributed GCPs and parallax points have been chosen for evaluation and shown on left image in Figure 10. Both derived ortho-image and 1/1000 scaled topographic maps can be seen as overlapped in Figure 11.

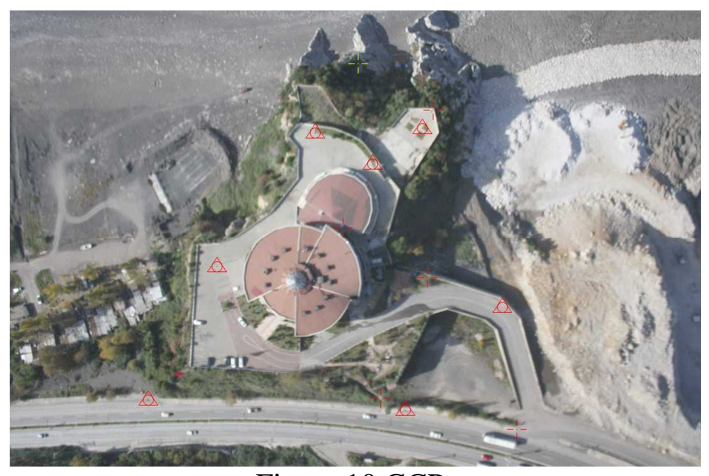

Figure $10 \mathrm{GCPs}$

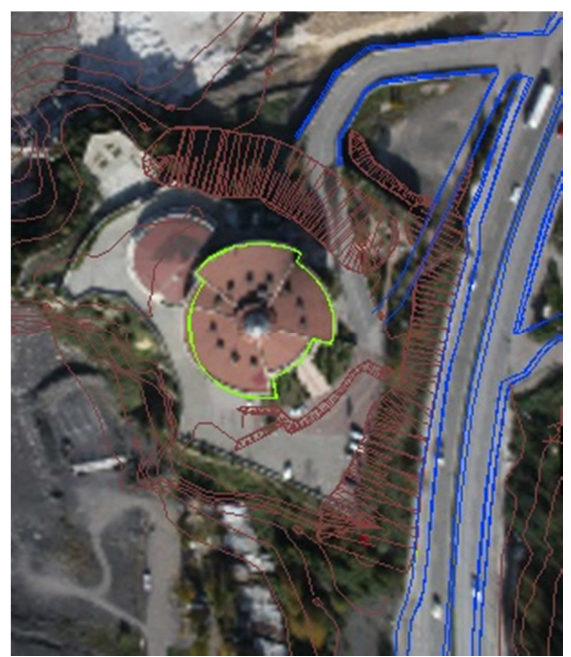

Figure 11 1/1000 Scaled Map Over The Ortho-Image

\section{CONCLUSIONS}

The data acquisition for mapping purposes by a model aircraft was aimed in the study.

A model aircraft and a non-metric digital camera 'Canon EOS450D' was used and the advantages of model aircraft technology in comparison with large scale photogrammetry was handled.

A part of Zonguldak coast line was used as test field.

Images were achieved and ortho-image has been successfully derived.

The Ground objects can be fully extracted from the images.

The model aircraft photogrammetric system can be used both for new map producing and updating of old maps like 1/1000 scaled maps derived in 1997 used in this study.

For mapping purposes the model aircraft photogrammetric system can provide low cost and time saving in comparison with today's photogrammetric map production period in local up to partially regional applications.

\section{ACKNOWLEDGEMENTS}

Thanks are going to Prof. Dr. Dursun Zafer Seker from Istanbul Technical University, Turkey for the supports to the study.

\section{REFERENCES}

Eisenbeiss H., 2009, UAV Photogrammetry, PhD Thesis, ETH Zurich, Switzerland

KRAUS, K. (2007): Photogrammetry - Geometry from Images and Laser Scans (2nd ed.). De Gruyter.

Neumann K. J., 2008, Trends For Digital Aerial Mapping Cameras, The International Archives of the Photogrammetry, Remote Sensing and Spatial Information Sciences. Vol. XXXVII. Part B1. Beijing

URL 1, http://www.letsgodigital.org/en/18066/canon-eos$\underline{450 \mathrm{~d} /}$ 